\title{
Editorial: Surgical Management Options in Proximal Hypospadias
}

\author{
Ricardo González ${ }^{1 *}$ and Miguel Alfedo Castellan ${ }^{2}$ \\ ${ }^{1}$ Pediatric Surgery and Urology, Kinder- und Jugendkrankenhaus AUF DER BULT, Hanover, Germany, ${ }^{2}$ Pediatric Urology, \\ Miami Children's Hospital, Miami, FL, United States
}

Keywords: hypospadias, complications, urethrocutaneous fistula, onlay repair, metal based flap

\section{Editorial on the Research Topic}

\section{Surgical Management Options in Proximal Hypospadias}

This research topic intended to highlight different philosophies and techniques for the correction of proximal hypospadias, a topic that continues to generate great controversy among pediatric urologists. Unfortunately, there were only four papers accepted to be included in this collection.

One paper dealt with the results of one-stage repair of mid- and proximal hypospadias, a second paper dealt with a technique to facilitate second-stage repairs when the urethral plate created in the first stage with a free graft was difficult to tabularize, a third paper reviewed the current status of tissue engineering for urethral reconstruction, and the fourth one dealt with the results of a modified Mathieu technique for repair of the megameatus/intact prepuce variant of hypospadias.

Authors from Germany (Hannover and Berlin) reported the results (measured by reoperation

OPEN ACCESS

Edited by:

Arjan Te Pas,

Leiden University, Netherlands

Reviewed by:

Yuval Bar-Yosef,

Dana-Dwek Children's Hospital, Israel Tariq O. Abbas,

Weill Cornell Medicine- Qatar, Qatar

${ }^{*}$ Correspondence:

Ricardo González ricardo_gonzalez33154@yahoo.com

Specialty section:

This article was submitted to Pediatric Urology,

a section of the journal

Frontiers in Pediatrics

Received: 21 February 2019

Accepted: 19 March 2019

Published: 11 April 2019

Citation:

González R and Castellan MA (2019)

Editorial: Surgical Management

Options in Proximal Hypospadias.

Front. Pediatr. 7:128

doi: 10.3389/fped.2019.00128 rate) in 49 children operated with a technique first described by the senior author in 1996 and followed for 2 years after the operation (González et al.). The technique consists of the preservation of the urethral plate whenever possible (48 of the 49 patients) and then creating an onlay urethroplasty using the outer preputial layer of a total preputial flap transposed ventrally through a buttonhole in its pedicle to avoid rotation. The penile curvature was corrected with chordectomy alone in 10 patients; 38 patients required a dorsal plication of the tunica albuginea and 1 patient required an additional ventral dermal graft. Success, defined as a straight penis, a glanular meatus, and the absence of voiding symptoms, was achieved in $77.5 \%$ of the patients with a single procedure. Complications included urethrocutaneous fistulas in $16 \%$ of the patients, glans dehiscence in $6 \%$ of the patients, and recurrent chordee in one patient. Of the 13 patients that had uroflow examinations, 11 had bell-shaped curves. This report would suggest that onestage repairs can achieve good results with fewer operations than the more commonly used staged techniques. Shortcomings of this report include relative short follow-up and lack of objective cosmetic evaluation.

A group from Vienna reported on 35 consecutive patients from a cohort of 250 hypospadias cases who completed both steps of a staged repair (Tonnhofer et al.). The original idea in this report, however, is based on the fact that in two-thirds of the patients, a midline incision of the graft was considered necessary to achieve tubularization during the second stage. With a mean follow-up of 18 months, the complication rate was $22 \%$, similar to that reported in the previously commented paper for a single-stage repair. The complication rate in this series was greater with the use of buccal mucosa than with the use of a free preputial graft. Complication rate in cases in which the plate was not incised (presumably because it was wider or of better "quality") was just $8.3 \%$. Despite these results, the authors conclude that a two-stage repair is the procedure of choice in the correction of severe hypospadias. Other shortcomings of this report include short follow-up, lack of objective criteria to decide to incise the plate, and lack of objective evaluation of the results of the urethroplasty, such as uroflow studies or calibration. Therefore, this paper adds a trick to facilitate 
the second stage, but the authors fail to demonstrate the real value of the maneuver. Perhaps it would be more productive to emphasize the need to have a very generous graft in the first stage and to wait until the graft is soft and pliable to perform the second stage.

A surgeon from Boston describes his experience with the use of a metal-based flap to repair the megameatus intact prepuce variant of hypospadias (MIP) (Cendron). Twenty-five patients operated in a 10-year period were divided into two groups. The first 10 cases underwent simple tubularization of the plate. One fistula developed. The next 15 cases underwent repair using a metal-based flap. There were no fistulas, but one patient experienced dehiscence of the glans. The author favors the metalbased flap technique, because in this series, it eliminated injury of the urethral plate during the dissection. Of course, the numbers are too small to draw definitive conclusions, but given the rarity of this condition, the author's opinion is worth considering.

A paper by authors from Qatar and Denmark analyzed the current knowledge of tissue-engineered material for

\section{REFERENCES}

1. Moscardi PRM, Gosalbez R, Castellan MA. Management of high-grade penile curvature associated with hypospadias in children. Front Pediatr. (2017) 5:189. doi: 10.3389/fped.2017.00189

Conflict of Interest Statement: The authors declare that the research was conducted in the absence of any commercial or financial relationships that could be construed as a potential conflict of interest. urethral replacement (Abbas et al.). The clinical experience cited is limited, but tissue engineering will certainly become a reality in the future that will benefit patients with undesirable results from surgical misadventures where local tissues are not available for reconstruction. The authors conclude that despite many significant advances, the search for a suitable tissue engineering approach for use in routine clinical applications continues.

A vital part of successful correction of severe hypospadias is the straightening of the penis. Although not included in this research topic, a recent article in Frontiers provides a comprehensive review of this topic and is highly recommended for surgeons interested in this topic (1).

\section{AUTHOR CONTRIBUTIONS}

All authors listed have made a substantial, direct and intellectual contribution to the work, and approved it for publication.
Copyright (C) 2019 González and Castellan. This is an open-access article distributed under the terms of the Creative Commons Attribution License (CC BY). The use, distribution or reproduction in other forums is permitted, provided the original author(s) and the copyright owner(s) are credited and that the original publication in this journal is cited, in accordance with accepted academic practice. No use, distribution or reproduction is permitted which does not comply with these terms. 